\title{
The role of ultrasound screening in reducing AAA mortality: a review
}

\author{
Kashif Imran Ahmad \\ Medical School, Liverpool University, Liverpool, England \\ *Corresponding author: Kashif Imran Ahmad; K.Ahmad@Lancaster.ac.uk
}

\begin{abstract}
Background: Men aged 65-79 are at the highest risk of having an abdominal aortic aneurysm (AAA) as well as a high incidence of rupture; this is treated as a surgical emergency, which has a total mortality of $75-90 \%{ }^{1-5}$ The diameter of an AAA proves to be the most useful risk factor in predicting mortality rates. ${ }^{6,7}$ Ultrasonography is widely accepted as an effective diagnostic imaging tool for detecting $A A A .^{8}$ Based on this, AAA elective repair is recommended to individuals with AAA of diameter $\geq 55 \mathrm{~mm} .{ }^{6,7}$ The problem lies in detecting individuals with $A A A$ as many are asymptomatic. ${ }^{9}$ The aim of this article is to determine whether a population-based ultrasound screening programme can significantly reduce AAA mortality using the critical appraisal skills programme (CASP) tool.

Method: Databases were searched for relevant literature. Studies were limited to randomised controlled trials (RCTs) that conducted a population-based screening programme using ultrasound. The results were further refined using inclusion and exclusion criteria. Four RCTs were selected for review.

Results: The pooled results of 125,576 men showed a significant reduction in the incidence of ruptured AAAs and AAA-related mortality in the intervention group. There was an insignificant reduction in all-cause mortality, and a significant increase in surgical rates in the intervention group. One of the reviewed studies looked at the effects of screening on 9,342 women and reported an insignificant reduction in AAA-related mortalities, all-cause mortality, and ruptured incidence.

Conclusion: There is evidence that a population-based screening has a significant effect in reducing AAA-related mortality in males aged 65-74. Due to the paucity of evidence in current available literature, no definitive conclusions can be drawn regarding population-based screening for AAA in women; it is suggested that future studies should be carried out to assess the benefits and relative risks of screening for this population.
\end{abstract}

Keywords: population; screening; ultrasonography; abdominal aortic aneurysms; mortality; systematic review.

\section{INTRODUCTION}

A n abdominal aortic aneurysm (AAA) occurs when there is a weakness in the arterial wall that leads to a dilatation of the aorta. ${ }^{1}$ The most common cause of AAA is due to arteriosclerosis, but it can also be caused by other means, such as trauma and infectious diseases. ${ }^{1}$ The majority of AAAs or AAA-related deaths occur in men aged 65-79 and account for a total mortality of $0.5 \% .^{2-4}$ The prevalence of AAA in this age group is $4-8 \%$ for men and $0.5-1.5 \%$ for women. ${ }^{10-13}$ AAA contributes significantly to the total mortality rate in developed countries such as the United States and the United Kingdom, where there are 13,000 deaths and 6,000 deaths per annum, respectively; ${ }^{14,15} 60 \%$ are AAArelated and the remainder are due to thoracic aortic aneurysms. ${ }^{15,16}$ Significant risk factors, such as age, gender, smoking, family history, and atherosclerotic disease, are known to contribute to the development of AAA. ${ }^{10}$

AAAs are generally asymptomatic for many years, but the area of weakness present in the aorta is prone to rupture if left untreated and can lead to fatality due to a rapid loss of blood. ${ }^{9,17}$ This major complication culminates in a large proportion of individuals dying before surgery or even before arriving at a hospital, therefore making this a surgical emergency. ${ }^{5,18}$ The mortality rate for such a complication after emergency surgery is 75-90\%; this gives it a poor prognosis when compared to those who undergo elective AAA surgery, which has a post-operative mortality rate of $3.3 \%{ }^{5,19,20}$ Despite the increase in surgical elective repairs, there are still a number of further complications that could occur, such as operative mortality and renal failure; ${ }^{21,22}$ these could be used to explain the continual rise of the age/sex standardised mortality from ruptured AAAs. ${ }^{23,24}$ AAA rupture depends on the size of the aneurysm and can be anticipated by a preclinical detectable phase, which provides an opportunity for a relatively low-risk surgical treatment when compared to that of the symptomatic phase. ${ }^{25}$ This poses the question of whether a screening programme is likely to be beneficial or not. 
Screening programmes have to meet a standard set by the World Health Organisation (WHO) and the Council of Europe before their introduction. ${ }^{23}$ In the United Kingdom, they are not implemented unless it has been approved by the National Screening Committee, which takes into consideration evidence from randomised control trials (RCTs). ${ }^{26}$ Originally, the National Screening Committee believed that there was insufficient evidence on which to recommend a populationbased screening programme, ${ }^{27}$ but the Committee has now reconsidered their evaluation based on current evidence. ${ }^{8}$ The National Health Service AAA screening programme is being implemented gradually across England, and full coverage is expected by March $2013 .^{25}$ This programme is aimed at men over 65 and measures the maximum diameter of the aorta during systole to determine whether an aneurysm is present or not. ${ }^{1}$ However, in many other western countries, no population-based screening programmes exist; the only means of screening available to individuals is via referrals from their general practitioner. ${ }^{25}$

Detecting AAA can be carried out in a number of ways using diagnostic imaging tools such as angiography, computed tomography (CT), magnetic resonance imaging (MRI), and ultrasound. ${ }^{1}$ In this review, only ultrasound is considered as a means of screening because it is universally accepted as the most effective screening tool for AAA as well as being widely reported in the current available literature. ${ }^{8,28,29}$ Ultrasonography is successful in detecting AAAs with an approximate sensitivity and specificity rate of $98 \%$ and $99 \%$, respectively. ${ }^{19,30,31}$ There has been a consistently high rate of attendance at programmes that range from $65 \%$ to $80 \%$. Approximately $85-90 \%$ of aneurysms detected by screening are too small to warrant surgery; therefore, they are monitored under surveillance programmes that have a 95\% attendance rate. ${ }^{23,24}$ Treatment for asymptomatic patients has been established based on the evidence from two $\mathrm{RCTs}^{6,7}$ that identified the most useful risk factor in predicting mortality as being the diameter of the AAA, quantifying a threshold of $55 \mathrm{~mm}$ or greater for a patient to be eligible for surgery.

The aim of this article is to determine whether a population-based ultrasound screening programme can significantly reduce AAA mortality using the critical appraisal skills programme (CASP) tool. This will be done by covering the following objectives:

(1) Perform a search of relevant literature pertaining to AAA screening via ultrasound.

(2) Use specific inclusion and exclusion criteria to refine the search method and acquire the evidence.

(3) Draw conclusions by critically reviewing the evidence using CASP tools.

\section{METHOD}

\section{Search method}

A review on the precision of ultrasound was not necessary, as direct evidence was available regarding this. The topic, AAA, was searched via databases and search engines to identify RCTs that determine the significance of AAA population-based screening using ultrasound. These included the Cochrane database, the current controlled trials database, MetaLib provided by Lancaster University, PubMed and ScienceDirect. ${ }^{32}$ These were further restricted with medical subject heading $(\mathrm{MeSH})$ terms to narrow the results (Table 1). ${ }^{32}$ Search methods employed were adapted to suit each database (Tables 2-5). Additional studies were further identified from the reference lists of articles that were relevant in the searches.

\section{Criteria for considering studies}

Twenty-three relevant articles were initially retrieved before being subjected to inclusion and exclusion criteria (Table 6). This then gave rise to four RCTs that were chosen to be reviewed and critically appraised using CASP tools. $^{33}$

\section{Quality of trials}

CASP was developed in 1993 in response to critically appraising research. ${ }^{34}$ It has helped form an evidencebased approach in the health care setting as well as providing a process in which research and evidence can be found and interpreted in an efficient and reliable fashion. ${ }^{34}$ The CASP tool is a derivative from CASP and consists of a series of questions that acts as a guide to check against particular biases that are linked to specific study designs. Use of CASP tools allows articles to be systematically appraised to assess the methodological quality, reliability, validity and also the extent to which they can be used to draw conclusions. ${ }^{33}$ Furthermore, assigning a scoring system to the CASP tool will allow similar studies to be scored in a similar fashion; doing so enables comparisons to be made as well as assessing any heterogeneity present. The studies selected will be subjected to the CASP tool relevant to RCTs.

\section{RESULTS}

Four RCTs that evaluated population-based screenings met the criteria from Table 6 and were reviewed Chichester, ${ }^{35}$ MASS, $^{36}$ Western Australia ${ }^{37}$ and Viborg. ${ }^{38}$

Table 1. MeSH terms.

MeSH term

Abdominal aortic aneurysms

Ultrasonography

Mass screening 
Table 2. Results for Cochrane database.

\begin{tabular}{ll}
\hline Search history & Number of results \\
\hline 1. Abdominal aortic aneurysms & 29 \\
2. Ultrasonography & 62 \\
3. Mass screening & 30 \\
4. $1+2+3$ & 6 \\
5. Rupture & 128 \\
$6 . \quad 4+5$ & 4 \\
\hline
\end{tabular}

Table 3. Results for current controlled trials database.

\begin{tabular}{|c|c|}
\hline Search history & Number of results \\
\hline 1. Abdominal aortic aneurysms & 28 \\
\hline 2. Ultrasonography & 334 \\
\hline 3. Mass screening & 10 \\
\hline 4. $1+2+3$ & 0 \\
\hline 5. $1+2$ & 2 \\
\hline 6. $1+3$ & 10 \\
\hline
\end{tabular}

Table 4. Results for PubMed.

\begin{tabular}{lr}
\hline Search history & Number of results \\
\hline 1. Abdominal aortic aneurysms & 11,002 \\
2. Ultrasonography & 210,710 \\
3. Mass screening & 84,486 \\
4. $1+2+3$ & 42 \\
5. Rupture & 31,311 \\
6. $4+5$ & 10 \\
\hline
\end{tabular}

Table 5. Results for ScienceDirect.

\begin{tabular}{|c|c|}
\hline Search history & Number of results \\
\hline 1. Abdominal aortic aneurysms & 27,933 \\
\hline 2. Ultrasonography & 90,585 \\
\hline 3. Mass screening & 203,182 \\
\hline 4. $1+2+3$ & 994 \\
\hline 5. Rupture & 234,364 \\
\hline 6. $4+5$ & 634 \\
\hline 7. $6+$ Randomised control trials & 124 \\
\hline 8. Limits were applied - 'English' & 30 \\
\hline
\end{tabular}

The characteristics, mortality caused by AAA, overall mortality, incidence of rupture and surgery for AAA of these studies are recorded in Tables 7-11. The studies were then critically appraised using CASP tools in Table 12 (taken directly from the Public Health Resource Unit)..$^{33}$

\section{Description of the studies}

The Chichester study ${ }^{35}$ identified 6,433 men and 9,342 women aged $65-80$ to participate; MASS ${ }^{36}-67,800$ men aged 65-74; Western Australia ${ }^{36}-41,000$ men

Table 6. Inclusion and exclusion criteria.

\section{Types of studies} Inclusion criteria

Exclusion criteria

Types of participants Inclusion criteria

Exclusion criteria

Types of interventions

Types of outcome measures
Outcome
1. Mortality
2. Incidence of rupture
3. Surgery required
4. Life expectancy

1. Trials, including patients that are symptomatic or asymptomatic for

2. Trials from any population

3. Both sexes

1. Ultrasound screening preferred (screening alone was to be considered as long as there was sufficient data for the outcomes)

aged 65-79; and Viborg ${ }^{38}-12,658$ men aged 65-73. In Chichester and MASS, participants were randomly selected from practice registers and health service lists in the United Kingdom. ${ }^{35,36}$ Participants for the Western Australia study were selected from the electoral roll in Perth, Australia, and Viborg participants were randomly selected from the health department in Viborg, Denmark. ${ }^{37,38}$ In all four studies, randomisation was computer generated. ${ }^{35-38}$ Participants were offered screening or a no-intervention control group for AAA on a 1:1 ratio; participants of the control group were followed with no contact throughout the study. Three of the studies established randomisation in groups to avoid a time lapse between randomisation and screening. ${ }^{35,36,38}$ The Western Australia screening sessions were carried out over a 32-month period for logistical reasons. ${ }^{37}$ This meant that men were not invited to the screening programme until a few months had passed, and as a result, 2,296 died before being screened. ${ }^{37}$ Participants for the Chichester and MASS studies were excluded prior to randomisation, if they resided in a nursing home or if their general practitioner declared they were not in a suitable condition for elective AAA repair. ${ }^{35,36}$ Similarly, the Western Australia study excluded individuals residing in a nursing home as well as those who resided too far to access a screening 
Table 7. Characteristics of each study.

\begin{tabular}{|c|c|c|c|c|c|}
\hline Characteristics of study & $\begin{array}{c}\text { Chichester study - } \\
\text { men }^{34}\end{array}$ & $\begin{array}{c}\text { Chichester study - } \\
\text { women }^{34}\end{array}$ & MASS $^{35}$ & $\begin{array}{l}\text { Western Australia } \\
\text { study }^{36}\end{array}$ & $\begin{array}{l}\text { Viborg county } \\
\text { study }^{37}\end{array}$ \\
\hline Location & UK & UK & UK & Australia & Denmark \\
\hline Age (years) & $65-80$ & $65-80$ & $65-74$ & $65-83$ & $65-73$ \\
\hline Participants (n) & 6,433 & 9,342 & 67,800 & 38,704 & 12,658 \\
\hline Mean follow-up (years) & 2.5 & 2.6 & 4.1 & 3.6 & 5.1 \\
\hline Randomised to screening (n) & 3,205 & 4682 & 33,839 & 19,352 & 6,339 \\
\hline Screening attendance (\%) & 73.0 & 65.0 & 80.0 & 70.0 & 76.0 \\
\hline Randomised to no screening ( $\mathrm{n}$ ) & 3,228 & 4,660 & 3,3961 & 19,352 & 6,319 \\
\hline
\end{tabular}

clinic. $^{37}$ No exclusions were noted for the Viborg study. Screening sessions were carried out at general practitioners for three of the studies. ${ }^{35-37}$ The Viborg study carried out screening in the county hospitals via a mobile screening team. ${ }^{38}$ All four studies used abdominal ultrasound as the screening method, and none were blinded due to their nature. ${ }^{35-38}$ An AAA was defined as having a diameter that was $\geq 30 \mathrm{~mm} \cdot{ }^{35-38}$ The outcome measures for all four studies were the number of identified surgeries that took place; ${ }^{35-38}$ Chichester also identified the incidence of ruptured aneurysms. ${ }^{35}$

Study $1^{35}$ - Influence of screening on the incidence of ruptured abdominal aortic aneurysm: 5-year results of a randomised controlled study (Chichester)

The acceptance rate was higher for men when compared to women $\left(73.0 \%\right.$ and $65.0 \%$ respectively). ${ }^{35}$ This declined with age; men and women aged 65 had a rate of $80.4 \%$ and $72.6 \%$, respectively, and men and women aged $76-80$ had an acceptance rate of $66.1 \%$ and $58.2 \%$, respectively. ${ }^{35}$ The indication for surgery in this study was that the AAA had an annual growth rate that was $\geq 10 \mathrm{~mm}$ or if the maximum diameter measured was $\geq 60 \mathrm{~mm}$. Ongoing surveillance was recorded; patients with aneurysms of 30-44 $\mathrm{mm}$ were rescanned on an annual basis and aneurysms of $45-59 \mathrm{~mm}$ were scanned quarterly. ${ }^{35}$ There was a significant increase in elective surgeries performed, odds ratio (OR) -2.42 ;
95\% confidence interval $(\mathrm{Cl})-[1.26-4.62]$ and the average follow-up was 2.5 years. ${ }^{35}$ There was independent classification of deaths that were thought to be AAA related. ${ }^{35}$ The mortality rate from AAA was regarded as not significant in the intervention group, OR $-0.59 ; 95 \% \mathrm{Cl}-[0.27-1.29]$. The overall mortality rates were regarded as not significant, OR $-1.07 ; 95 \%$ $\mathrm{Cl}-[0.93-1.22]$. Fewer ruptured aneurysms were seen in the screened group, OR $-0.45 ; 95 \% \mathrm{Cl}-[0.21-0.99]$. Women were analysed separately from men to assure homogeneity was achieved in the results, but no benefit was seen; AAA-related mortality - OR $-1.99 ; 95 \%$ $\mathrm{Cl}-$ [0.36-10.88]; all-cause mortality, OR - 1.06; 95\% $\mathrm{Cl}-[0.93-1.21]$; and ruptured incidence, OR -1.49; $95 \% \mathrm{Cl}-[0.25-8.94]$. Full results are available in Tables 8-11.

Study $2^{36}$ - The multi-centre aneurysm screening study (MASS) into the effect of abdominal aortic aneurysm screening on mortality in men: a randomised controlled trial (MASS)

There was an acceptance rate of $80.0 \% .{ }^{36}$ Referrals were issued if the aneurysm was $\geq 55 \mathrm{~mm}$ or growing at a rate $\geq 10 \mathrm{~mm}$ per year. Surveillance was carried out annually, if the aneurysm was $30-44 \mathrm{~mm}$ and quarterly if it was $44-54 \mathrm{~mm}^{36}$ Thirty-one of the three hundred and twenty-two patients who had surgery did not meet the criteria for elective AAA surgery. ${ }^{36}$ There was a

Table 8. Mortality caused by AAA.

\begin{tabular}{|c|c|c|c|c|}
\hline AAA Mortality - study & $\begin{array}{l}\text { Patients screened } \\
\qquad(\mathrm{n} / \mathrm{N})\end{array}$ & $\begin{array}{l}\text { Patients unscreened } \\
\qquad(\mathrm{n} / \mathrm{N})\end{array}$ & Weight (\%) & $\begin{array}{c}\text { Odds ratio (95\% } \\
\text { confidence interval) }\end{array}$ \\
\hline Chichester - men $^{34}$ & $10 / 3,205$ & $17 / 3,228$ & 10.0 & $0.59[0.27-1.29]$ \\
\hline MASS $^{35}$ & $65 / 33,839$ & $113 / 33,961$ & 65.9 & $0.58[0.42-0.78]$ \\
\hline Western Australia ${ }^{36}$ & $18 / 19,352$ & $25 / 19.352$ & 16.8 & $0.72[0.39-1.32]$ \\
\hline Viborg County ${ }^{37}$ & $6 / 6,339$ & $19 / 6,319$ & 7.3 & $0.31[0.13-0.79]$ \\
\hline Total - men & $99 / 62,735$ & $174 / 62,860$ & 100 & $0.57[0.45-0.74]$ \\
\hline Total - excluding Viborg County & $93 / 56,396$ & $135 / 56,541$ & - & $0.60[0.47-0.78]$ \\
\hline Total - excluding MASS - sensitivity analysis & $28 / 28,896$ & $61 / 28,899$ & - & $0.56[0.36-0.88]$ \\
\hline Chichester - women ${ }^{34}$ & $4 / 4,682$ & $2 / 4,660$ & 100 & $1.99[0.36-10.88]$ \\
\hline Total - women & $4 / 4,682$ & $2 / 4,660$ & 100 & $1.99[0.36-10.88]$ \\
\hline
\end{tabular}


Table 9. Overall mortality.

\begin{tabular}{lcccc}
\hline Overall mortality - study & $\begin{array}{c}\text { Patients screened } \\
(\mathrm{n} / \mathrm{N})\end{array}$ & $\begin{array}{c}\text { Patients } \\
\text { unscreened (n/N) }\end{array}$ & Weight (\%) & $\begin{array}{c}\text { Odds ratio (95\% confidence } \\
\text { interval) }\end{array}$ \\
\hline${\text { Chichester }- \text { men }^{34}}_{\text {MASS }^{35}}$ & $532 / 3,205$ & $508 / 3,228$ & 7.8 & $1.07[0.93-1.22]$ \\
Western Australia $^{36}$ & $3,750 / 33,839$ & $3,855 / 33,961$ & 60.2 & $0.97[0.93-1.02]$ \\
Viborg County $^{37}$ & $2,232 / 19,352$ & $2,571 / 19,352$ & 32.0 & $0.85[0.80-0.90]$ \\
Total - men & $\mathrm{N} / \mathrm{A}$ & $\mathrm{N} / \mathrm{A}$ & $\mathrm{N} / \mathrm{A}$ & $\mathrm{N} / \mathrm{A}$ \\
Chichester - women $^{34}$ & $6,514 / 62,735$ & $6,934 / 62,860$ & 100 & $0.95[0.85-1.07]$ \\
Total - women & $503 / 4,682$ & $476 / 4,660$ & 100 & $1.06[0.93-1.21]$ \\
\end{tabular}

significant increase in elective surgeries performed, OR $-2.45 ; 95 \% \mathrm{Cl}-[2.02-2.97]$, and the average follow-up was 4.1 years. ${ }^{36}$ Cause of death was noted by death certificate only. ${ }^{36}$ The mortality rate from AAA was regarded as significant, with a strong reduction in the intervention group, $\mathrm{OR}-0.58 ; 95 \% \mathrm{Cl}-[0.42-0.78]$. The overall mortality rates were regarded as not significant, OR $-0.97 ; 95 \% \mathrm{Cl}-[0.93-1.02]$. Full results are available in Tables 8-11.

Study $3^{37}$ - Population-based randomised controlled trial on impact of screening on mortality from abdominal aortic aneurysm (Western Australia)

There was an acceptance rate of $70.0 \% .^{37}$ Surgery indications were left to individual surgeons to decide. A suggested surveillance programme was sent via letter to individuals recommending annual screening, if their aneurysm was $30-39 \mathrm{~mm}$, and twice annually, if it was $40-49 \mathrm{~mm} .{ }^{37}$ Referrals for surgery with aneurysms that were $\geq 45 \mathrm{~mm}$ were left up to discretion of the physician. ${ }^{37} \mathrm{~A}$ vascular referral was issued, if the aneurysm was $\geq 50 \mathrm{~mm} .{ }^{37}$ No other means of contact were carried out by the investigators for either group. There was a significant increase in elective surgeries performed, OR $-1.88 ; 95 \% \mathrm{Cl}-[1.38-2.56]$, and the average follow-up was 3.6 years. ${ }^{37}$ There was independent classification of deaths that were thought to be AAA related. ${ }^{37}$ The mortality rate from AAA was regarded as not significant in the intervention group, OR $-0.72 ; 95 \% \mathrm{Cl}-[0.39-1.32]$. The overall mortality rates were regarded as significant but are only reported from the point of screening, not randomisation, OR $0.85 ; 95 \% \mathrm{Cl}-[0.80-0.90]$. Full results are available in Tables 8-11.

Study $4^{38}$ - Hospital costs and benefits of screening for abdominal aortic aneurysms. Results from a randomised population screening trial (Viborg)

There was an acceptance rate of $76.0 \% .^{38}$ Referrals were issued, if the aneurysm was $\geq 55 \mathrm{~mm} .{ }^{38}$ Surveillance was carried out annually, if the aneurysm was $\geq 30 \mathrm{~mm}^{38}$ There was a non-significant increase in elective surgeries performed, OR $-1.46 ; 95 \% \mathrm{Cl}-$ [0.98-2.18], and the average follow-up was 5.1 years. ${ }^{38}$ The mortality rate from AAA was regarded as significant, with a strong reduction in the intervention group, OR $0.31 ; 95 \% \mathrm{Cl}-[0.13-0.79]$. As this study only identified deaths that occurred within the hospital setting, it cannot be compared to the other studies. There was insufficient data to calculate overall mortality rates. Full results are available in Tables $8-11$.

\section{META-ANALYSIS OF STUDIES}

The meta analyses of the results are available in Tables 8-11. Overall, the combined number of participants totaled at 125,576 men, with an attendance rate ranging from $70 \%$ to $80 \%$. The pooled odds ratio and confidence interval (excluding the Viborg study due to reliability of results - OR $-0.60 ; 95 \% \mathrm{Cl}-[0.47-0.78]$ ) supported the use of ultrasound screening for AAA, as it showed a

Table 10. Incidence of ruptured AAA.

\begin{tabular}{lcccc}
\hline Incidence of rupture - study & $\begin{array}{c}\text { Patients screened } \\
(\mathrm{n} / \mathrm{N})\end{array}$ & $\begin{array}{c}\text { Patients } \\
\text { unscreened (n/N) }\end{array}$ & Weight (\%) & $\begin{array}{c}\text { Odds ratio (95\% confidence } \\
\text { interval) }\end{array}$ \\
\hline${\text { Chichester - } \text { men }^{34}}_{\text {MASS }^{35}}$ & $9 / 3,205$ & $20 / 3,228$ & 100 & $0.45[0.21-0.99]$ \\
Western Australia $^{36}$ & $\mathrm{~N} / \mathrm{A}$ & $\mathrm{N} / \mathrm{A}$ & $\mathrm{N} / \mathrm{A}$ & $\mathrm{N} / \mathrm{A}$ \\
Viborg County $^{37}$ & $\mathrm{~N} / \mathrm{A}$ & $\mathrm{N} / \mathrm{A}$ & $\mathrm{N} / \mathrm{A}$ & $\mathrm{N} / \mathrm{A}$ \\
Total - men $_{\text {Chichester - women }}^{34}$ & $\mathrm{~N} / \mathrm{A}$ & $\mathrm{N} / \mathrm{A}$ & $\mathrm{N} / \mathrm{A}$ & $0.45[0.21-0.99]$ \\
Total - women $^{34}$ & $9 / 3,205$ & $20 / 3,228$ & 100 & $1.49[0.25-8.94]$ \\
\hline
\end{tabular}


Table 11. Surgery for AAA.

\begin{tabular}{lcccc}
\hline Surgery for AAA - study & $\begin{array}{c}\text { Patients screened } \\
(\mathrm{n} / \mathrm{N})\end{array}$ & $\begin{array}{c}\text { Patients } \\
\text { unscreened (n/N) }\end{array}$ & Weight (\%) & $\begin{array}{c}\text { Odds ratio (95\% confidence } \\
\text { interval) }\end{array}$ \\
\hline Chichester - men $^{34}$ & $31 / 3,205$ & $13 / 3,228$ & 11.2 & $2.42[1.26-4.62]$ \\
MASS $^{35}$ & $354 / 33,839$ & $146 / 33,961$ & 38.8 & $2.45[2.02-2.97]$ \\
Western Australia $^{36}$ & $116 / 19,352$ & $62 / 19,352$ & 28.3 & $1.88[1.38-2.56]$ \\
Viborg County $^{37}$ & $60 / 6,339$ & $41 / 6,319$ & 21.8 & $1.46[0.98-2.18]$ \\
Total - men & $561 / 62,735$ & $262 / 62,860$ & 100 & $2.03[1.59-2.59]$ \\
\hline
\end{tabular}

reduction in AAA-related mortalities, OR $-0.57 ; 95 \%$ $\mathrm{Cl}-[0.45-0.74]$. The MASS had the largest weight in the pooled results with the narrowest $\mathrm{Cl}$. Sensitivity analysis revealed that when the MASS results were removed, the other three studies still showed a significant reduction in AAA mortalities, OR $-0.56 ; 95 \% \mathrm{Cl}-[0.36-0.88]$. The all-cause mortality results were unavailable for the Viborg study, so the Chichester, MASS and Western Australia studies were pooled. They showed that screening was not significant in reducing all-cause mortality, OR $-0.95 ; 95 \% \mathrm{Cl}-[0.85-1.07]$. The surgery for AAA results showed a significant increase in the screening group, OR - 2.03; 95\% Cl - [1.59-2.59].

\section{DISCUSSION}

The pooled data from the four RCTs have shown evidence that ultrasound screening significantly reduced AAA-related mortalities by $43.1 \%$. The absolute risk in AAA-related mortality reduction (per 100,000) for the Chichester study, MASS, Western Australia and Viborg study is 36.2, 214.2, 140.7 and 206.0, respectively. These values are approximations for population-based screening. Despite the results, there are some inconsistencies present. MASS evaluated mortality solely based on death certificates, whereas the other studies used independent evaluators to assess patients that were suspected of an AAA-related mortality. This may

Table 12. Critical appraisal of RCTs using CASP tools.

\section{CASP tools $-\mathrm{RCT}^{33}$ \\ 1. Did the study ask a clearly focused question? \\ 2. Was this a randomised controlled trial $(\mathrm{RCT})$ and was it appropriately so? \\ 3. Were participants appropriately allocated to intervention and control groups?}

4. Were participants, staff and study personnel 'blind' to participants' study group?

5. Were all of the participants who entered the trial accounted for at its conclusion?

6. Were the participants in all groups followed up and data collected in the same way?

7. Did the study have enough participants to minimise the play of chance?

8. How were the results presented, and what were the main results?

9. How precise were these results?

10. Were all important outcomes considered so the results can be applied?

$$
\begin{array}{ll}
\frac{\text { SCORING }}{\text { YES }=\sqrt{ }}=2 & \text { TOTAL } \\
\text { PARTIALLY }=-=1 & \\
\text { NO }=\times=0 &
\end{array}
$$

\begin{tabular}{|c|c|c|c|}
\hline STUDY $1^{34}$ & STUDY $2^{35}$ & STUDY $3^{36}$ & STUDY $4^{37}$ \\
\hline$\checkmark$ & $\checkmark$ & $\checkmark$ & $\checkmark$ \\
\hline$\sqrt{ }$ & $\checkmark$ & $\checkmark$ & $\sqrt{ }$ \\
\hline- & - & - & $\checkmark$ \\
\hline$\times$ & $\times$ & $\times$ & $\times$ \\
\hline- & $\checkmark$ & $\checkmark$ & $\checkmark$ \\
\hline$\sqrt{ }$ & $\sqrt{ }$ & $\sqrt{ }$ & $\checkmark$ \\
\hline- & $\checkmark$ & $\checkmark$ & $\checkmark$ \\
\hline$\checkmark$ & $\checkmark$ & $\checkmark$ & $\checkmark$ \\
\hline$\sqrt{ }$ & $\checkmark$ & $\checkmark$ & $\checkmark$ \\
\hline- & $\checkmark$ & - & $\times$ \\
\hline $14 / 20$ & $17 / 20$ & $16 / 20$ & $16 / 20$ \\
\hline
\end{tabular}


have led to a possible over-estimation of AAA-related mortality, thus introducing bias in cases where cause of death was equivocal. Conversely, the results could show an under-estimation of AAA-related mortalities, if the cause of death is falsely attributed to any cause other than AAA-related.

Results showed that there was no significant evidence to support a reduction in all-cause mortality. This is to be expected, as AAA-related mortality only accounts for a small number of deaths in elderly men. Nonetheless, there is heterogeneity present in the results of the Western Australia study, which shows a decrease in allcause mortality $(n=339)$ in the screening group when compared to the control group. Only a difference of seven deaths was recorded that favoured screening for AAA-related mortalities; these results suggest that the difference in all-cause mortalities may be due to a flaw in the design of the study. Between randomisation and screening, there was a lapse of 32 months, during which 2,296 individuals selected for the study died. The following analysis of the results was carried out from the date screening was commenced and not from date of randomisation, which possibly introduced a further study design error.

Only the Chichester study included women in its study in which the evidence pointed towards a nonsignificant benefit from screening in reducing AAArelated or even all-cause mortality. However, due to an insufficient number of participants, the validity of these results is questionable.

Although all studies reported the same outcome, their methods differed. With AAA detection in the Western Australia study, individuals were referred back to their general practitioner for further evaluation and treatment. In the remaining studies, surveillance programmes were carried out and operated. The Viborg study only assessed mortalities from hospital records; this may have led to a large number of deaths from the community being overlooked. Furthermore, the degree to which these studies can be generalised to other countries is limited, as no one reported data on ethnicity, race or geographical location.

There were a number of limitations that applied in this review. Articles were limited to those that were free or available via an Athens account; this restricted the amount of available literature as many articles required a subscription. Further to this, only articles in English (including translations) were analysed and included. The retrieved articles were then subjected to limitations based on the author's judgement, thus incurring a form of selection bias. Conclusions regarding female subjects drawn from the review results could have been more valid and reliable, if the Chichester study had recruited a larger number of female participants, as well as having a representative number of females included in the other studies. If all studies used the same method for randomisation and recording mortality, then the results could have been more accurately compared.

Although discrepancies are present in both the study designs and limitations of this review, overall they have had a minute effect on AAA-mortality, as the MASS results accounted for a large weight of the pooled results. The benefit of population-based screening is becoming evident as there are an increasing number of studies with comparable methods that are researching AAA screening via ultrasound. Nevertheless, the rate of elective AAA repair will increase, which may cause mortalities in individuals who have aneurysms detected via screening that may possibly never rupture.

\section{CONCLUSION}

The use of the CASP tool to review the evidence indicates that population-based ultrasound screening has a significant effect in reducing AAA-related mortality in males aged 65-74. The risk of mortality from treatment is lower than that of ruptured aneurysms but still presents as a significant factor. Due to the paucity of evidence in current available literature, no definitive conclusions can be drawn regarding population-based screening for AAA in women, so it is therefore suggested that future studies should be carried out to assess the benefits and relative risks for this population. Cost-effectiveness, quality of life and the harms of ultrasound screening have not been specifically addressed in this review due to limited data, but it is acknowledged that these factors need to be carefully considered and evaluated before any population-based screening programme is implemented.

Conflict of interest and funding: There has been no conflictsof-interest or financial-interest.

\section{REFERENCES}

1. Marshall G. 1996. Screening for abdominal aortic aneurysm - does it fulfil the criteria for mass screening? Radiography 2:3-9. http://dx.doi.org/10.1016/S1078-8174(96)90029-2.

2. Scott R, Vardulaki K, Walker N, Day N, Duffy S, Ashton H. 2001. The long-term benefits of a single scan for abdominal aortic aneurysm (AAA) at age 65. Eur J Vasc Endovasc 21: 535-40. http://dx.doi.org/10.1053/ejvs.2001.1368.

3. Scott R, Bridgewater S, Ashton H. 2002. Randomized clinical trial of screening for abdominal aortic aneurysm in women. Brit J Surg 89:283-5. http://dx.doi.org/10.1046/j.0007-1323.2001.02014.x. 4. Heronm M, Hoyert D, Murphy S, Xu J, Kochanek K, Tejada-Vera B 2009. Deaths: final data for 2006. Natl Vital Stat Rep 57(14):34-86.

5. Bown M, Sutton A, Bell P, Sayers R. 2002. A meta-analysis of 50 years of ruptured abdominal aortic aneurysm repair. Brit J Surg 89:714-30. http://dx.doi.org/10.1046/j.1365-2168.2002.02122.x. 
6. UK Small Aneurysm Trial Participants. Long-term outcomes of immediate repair compared with surveillance of small abdominal aortic aneurysms. New Engl J Med 2002; 346(19): 1445-52. http://dx.doi.org/10.1056/NEJMoa013527.

7. Lederle F, Wilson S, Johnson G, Reinke D, Littooy F, Acher C, et al. 2002. Immediate repair compared with surveillance of small abdominal aortic aneurysms. New Engl J Med 346(19):1437-44. http://dx.doi.org/10.1056/NEJMoa012573. 8. NHS (2011). NHS evidence - screening. Available from: http://www.library.nhs.uk/screening/SearchResults.aspx? catID=15441\&tabID=289\&pgIndex=0\& [cited 15 April 2011]. 9. Darling R, Messina C, Brewster D, Ottinger L. 1977. Autopsy study of unoperated abdominal aortic aneurysms. The case for early resection. Circulation 56(2):161-4.

10. Lederle F, Johnson G, Wilson S, Chute E, Hye R, Makaroun $\mathrm{M}$, et al. 2000. The aneurysm detection and management study screening program: validation cohort and final results. A neurysm detection and management veterans affairs cooperative study investigators. Arch Intern Med 160:1425-30. http://dx.doi.org/10.1001/archinte.160.10.1425. 11. Lederle F, Johnson G, Wilson S. 2001. Abdominal aortic aneurysm in women. J Vasc Surg 34:122-6.

12. Lindholt J, Henneberg $E$, Fasting $H$, Juul S. 1996. Hospital based screening of 65-73 year old men for abdominal aortic aneurysms in the county of Viborg, Denmark. J Med Screen 3:43-6. http://dx.doi.org/10.1177/096914139600300111.

13. Vardulaki K, Pervost T, Walker N, Day N, Wilmink A, Quick C, et al. 1999. Incidence among men of asymptomatic abdominal aortic aneurysms: estimates from 500 screen detected cases. J Medl Screen 6(1):50-4. http://dx.doi.org/10.1136/jms.6.1.50.

14. Earnshaw J, Shaw E, Whyman M, Poskitt K, Heather B. 2004. Screening for abdominal aortic aneurysms in men. Brit Med J 328(7448):1122-4. http://dx.doi.org/10.1136/bmj.328.7448.1122.

15. Kochanek K, Xu J, Murphy S, Miniño A, Kung H. 2011. Deaths: preliminary data for 2009. Natl Vital Stat Rep 59(11):1-69. 16. Gillum R. 1995. Epidemiology of aortic aneurysm in the United States. J Clin Epidemiol 48:1289-98.

17. Watson JE. Medical-surgical nursing and related physiology. 2nd ed. Philadelphia: W B Saunders; 1979, p. 351. 18. Adam D, Mohan I, Stuart W, Bain M, Bradbury A. 1999. Community and hospital outcome from ruptured abdominal aortic aneurysm within the catchment area of a regional vascular surgical service. J Vasc Surg 30:922-8. hitp://dx.doiory/10.1016/ 19. Nusbaum J, Freimanis A, Thomford N. 1971. Echography in the diagnosis of abdominal aortic aneurysm. Brit J Surg 102:385-8. http://dx.doi.org/10.1001/archsurg.1971.01350040147028. 20. Fleming C, Whitlock E, Beil T, Lederrle F. 2005. Screening for abdominal aortic aneurysm: a best-evidence systematic review for the U.S. preventive services task force. Ann Intern Med 142(3):203-11. http://dx.doi.org/10.7326/0003-4819-142-3-200502010-00012. 21. Williamson W, Nicoloff A, Taylor LJ, Moneta G, Landry G, Porter J. 2001. Functional outcome after open repair of abdominal aortic aneurysm. J Vasc Surg 33:913-20. . $_{\text {mva.2001.115164. }}^{\text {hth:/10.1067/ }}$ 22. Huber T, Wang J, Derrow A, Dame D, Ozaki C, Zelenock G, et al. 2001. Experience in the United States with intact $\begin{gathered}\text { htp:/// } \\ \text { dx.do.org/10.106 }\end{gathered}$ abdominal aortic aneurysm repair. J Vasc Surg 33:304-10, ${ }_{\text {mva.200.112703 }}^{71}$ 23. Lindholt J. Considerations and experiences of screening for abdominal aortic aneurysms. Copenhagen: Fadl's Forlag; 1998.
24. Wilmink A, Quick C. 1998. Epidemiology and potential for prevention of abdominal aortic aneurysm. Brit J Surg 85(2):155-62. http://dx.doi.org/10.1046/j.1365-2168.1998.00714.x.

25. Ferket B, Grootenboer N, Colkesen E, Visser J, Sambeek M, Spronk $S$, et al. Systematic review of guidelines on abdominal aortic aneurysm screening. J Vasc Surg 2011. http:// dx.doi.org/10.1016/j.jvs.2010.10.118.

26. Health Departments of the United Kingdom (1998). First Report of the National Screening Committee. National Screening Committee, pp. 1-45. Available from: http://www. dh.gov.uk/prod_consum_dh/groups/dh_digitalassets/ documents/digitalasset/dh_084456.pdf [cited 15 April 2011]. 27. Health Departments of the United Kingdom (2000). Second Report of the UK National Screening Committee. National Screening Committee, pp. 1-29. Available from: http://www. dh.gov.uk/prod_consum_dh/groups/dh_digitalassets/@dh/ @en/documents/digitalasset/dh_4014560.pdf [cited 15 April 2011].

28. McGregor JC, Pollock JG, Anton HC. 1975. The value of ultrasonography in the detection of abdominal aortic aneurysms. Scot Med J 20:133-7.

29. Leger A, Spencely M, McCollum C, Mossa M. 1996. Screening for abdominal aortic aneurysms: a computer assisted cost-utility analysis. Eur J Vasc Endovasc 11:183-90. 30. Wilmink A, Forshaw M, Quick C, Hubbard C, Day N. 2002. Accuracy of serial screening for abdominal aortic aneurysms by ultrasound. J Med Screen 9:125-7. http///dx.doi.org/10.1136/jms.9.3.125. 31. Lindholt J, Vammen S, Juul S, Henneberg E, Fasting $\mathrm{H}$. 1999. The validity of ultrasonographic scanning as screening method for abdominal aortic aneurysm. Eur J Vasc Endovasc 17(6):472-5. http://dx.doi.org/10.1053/ejvs.1999.0835.

32. Greenhalgh $T$ How to read a paper - the basics of evidence-based medicine. 4th ed. BMJ Books. London: WileyBlackwell; 2010.

33. NHS (2011). CASP tools - RCT appraisal tool. Available from: http://www.sph.nhs.uk/sph-files/casp-appraisal-tools/rctap9praisaltool.pdf/view [cited 17 April 2011].

34. NHS (2011). Critical appraisal skills programme. Available from: http://www.sph.nhs.uk/what-we-do/public-healthworkforce/resources/critical-appraisals-skills-programme/ [cited 17 April 2011].

35. Scott R, Wilson N, Ashton H, Kay D. 1995. Influence of screening on the inicidence of ruptured abdominal aortic aneurysm: 5-year results of a randomized controlled study. Brit J Surg 82(8):1066-70. http://dx.doi.org/10.1002/bjs.1800820821. 36. Ashton H, Buxton M, Day N, Kim L, Marteau T, Scott R, et al. 2002. The multicentre aneurysm screening study (MASS) into the effect of abdominal aortic aneurysm screening on mortality in men: a randomised controlled trial. Lancet 360(9345):1531-39. http://dx.doi.org/10.1016/S0140-6736(02)11522-4. 37. Norman $P$, Jamrozik K, Lawrence-Brown $M$, Le $M$, Spencer C, Tuohy R, et al. 2004. Population based randomised controlled trial on impact of screening on mortality from

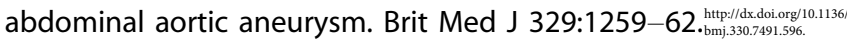
38. Lindholt J, Juul S, Fasting H, Henneberg E. 2002. Hospital costs and benefits of screening for abdominal a ortic aneurysms. Results from a randomised population screening trial. Eur J Vasc Endovasc 23(1):55-60. http://dx.doi.org/10.1053/ejvs.2001.1534. 